\title{
Mechanical testing of the IFMIF HFTM-DC prototype during operation in the HELOKA-LP helium loop
}

\section{Author: Georg Schlindwein}

The High Flux Test Module - Double Compartment (HFTM DC)

- Prototype design is derived from the IFMIF HFTM-V with a reduced number of compartments from 8 to 2

- Construction at 1:1 scale

$\rightarrow$ cooling flow conditions identical to the original IFMIF-HFTM

- Compartment A loaded with 3 full operational rigs (design point temperature $350^{\circ} \mathrm{C}$ ), compartment $\mathrm{B}$ with rig mock-ups

Background:

The IFMIF-HFTM (International Fusion Irradiation Facility) is a dedicated device to irradiate material specimens with neutrons having an energy spectrum peak near $14 \mathrm{MeV} \rightarrow$ Design database for DEMO

Key features:

- Low pressure (0.3 MPa a.) helium gas cooled pressure vessel

- Low neutron attenuation in beam direction by a thin-walled container design

- Effective utilisation of the limited high flux region $\left(500 \mathrm{~cm}^{3} @ \geq 20 \mathrm{dpa/fpy}{ }^{1}\right)$ by the use of mini cooling channels

displacements per atom per full power year

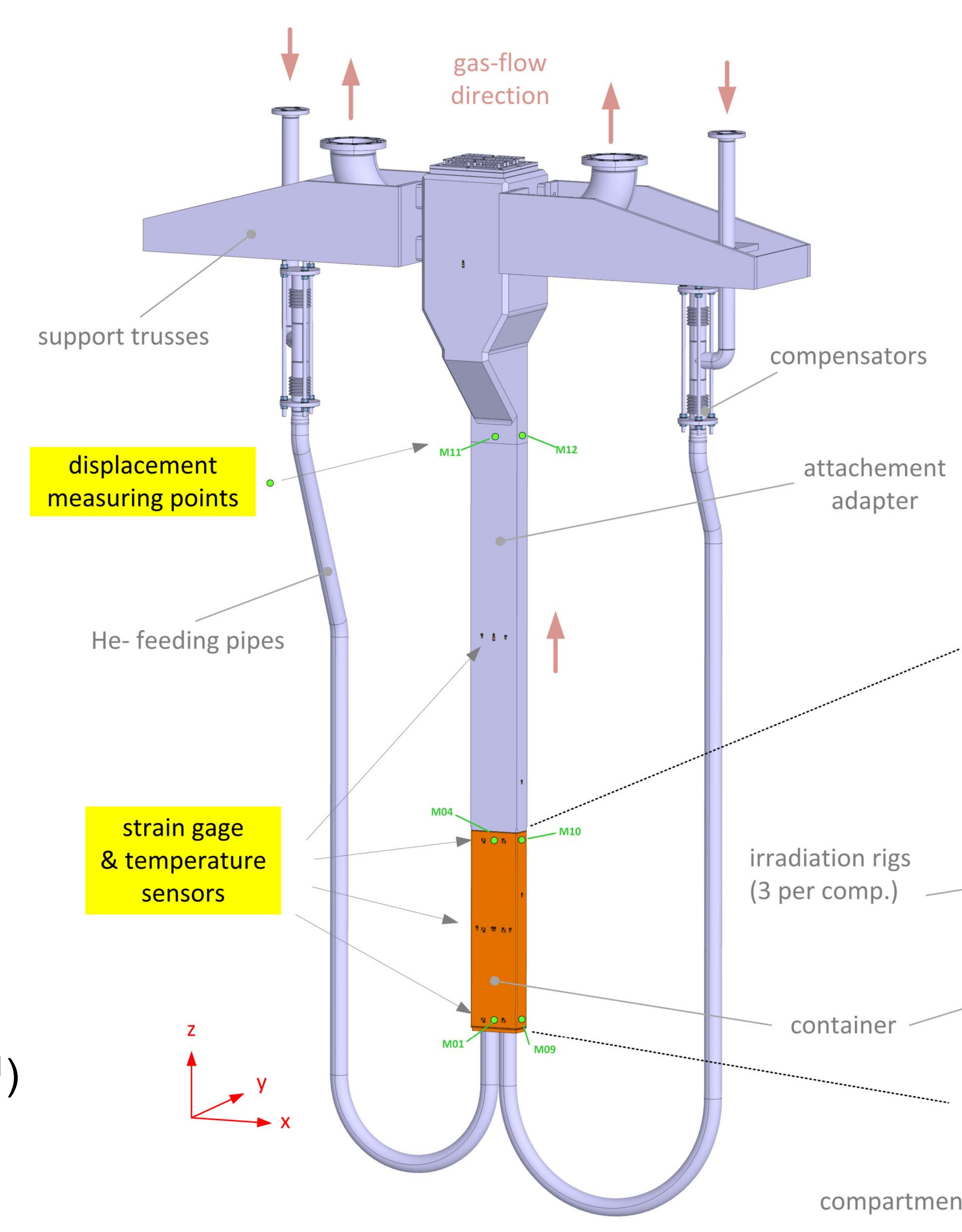

Instrumentation:

- 12 digital dial indicators (displacement)

40 temperature corrected

strain gage sensors

\section{Static pressure test}

Proof of safety at room temperature and a test pressure of $0.545 \mathrm{MPa}(\mathrm{g})$ Nominal operation pressure: $0.3 \mathrm{MPa}\left(\mathrm{abs}_{.}\right.$)
Experimental results

FEM simulation
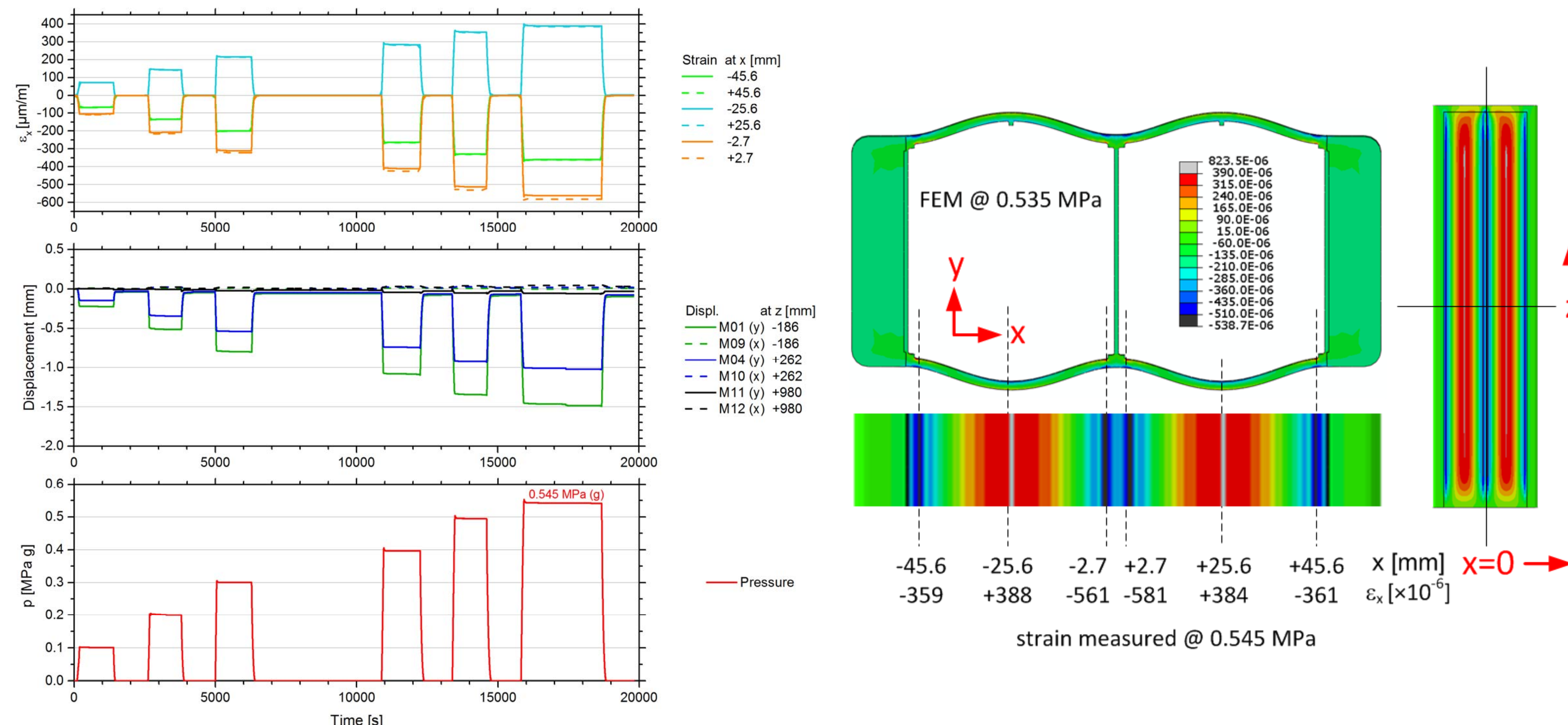

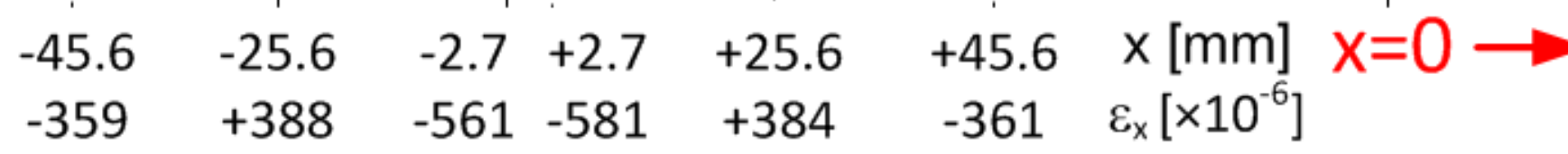

strain measured @ $0.545 \mathrm{MPa}$
- Symmetry of the strain field $\varepsilon_{x}$ at container centre-line $(z=0)$ in $x$-direction

- $1.5 \mathrm{~mm}$ displacement of container towards $y$-direction (towards IFMIF target) due to asymmetry in module design, no displacement in lateral $x$-direction

- Pressure proportionality of measured strains and deflections

- Strain measurements consistent to FEM simulation studies

- Magnitude of (-)600 $\mu \mathrm{m} / \mathrm{m}$ at $0.545 \mathrm{MPa}(\mathrm{g})$ corresponding to $120 \mathrm{MPa}$ local stress

- Detected leakage rate approx. $20 \mathrm{~Pa} \cdot \mathrm{L} \cdot \mathrm{S}^{-1}$

- No significant residuals of strain and displacement after pressure relief

$\rightarrow$ No indication for a plastic deformation or damage

\section{Safety of the HFTM-DC prototype successfully confirmed}

Thermal test SCN TH-006

Demonstration of the

maximum possible capsule pre-heating temperature
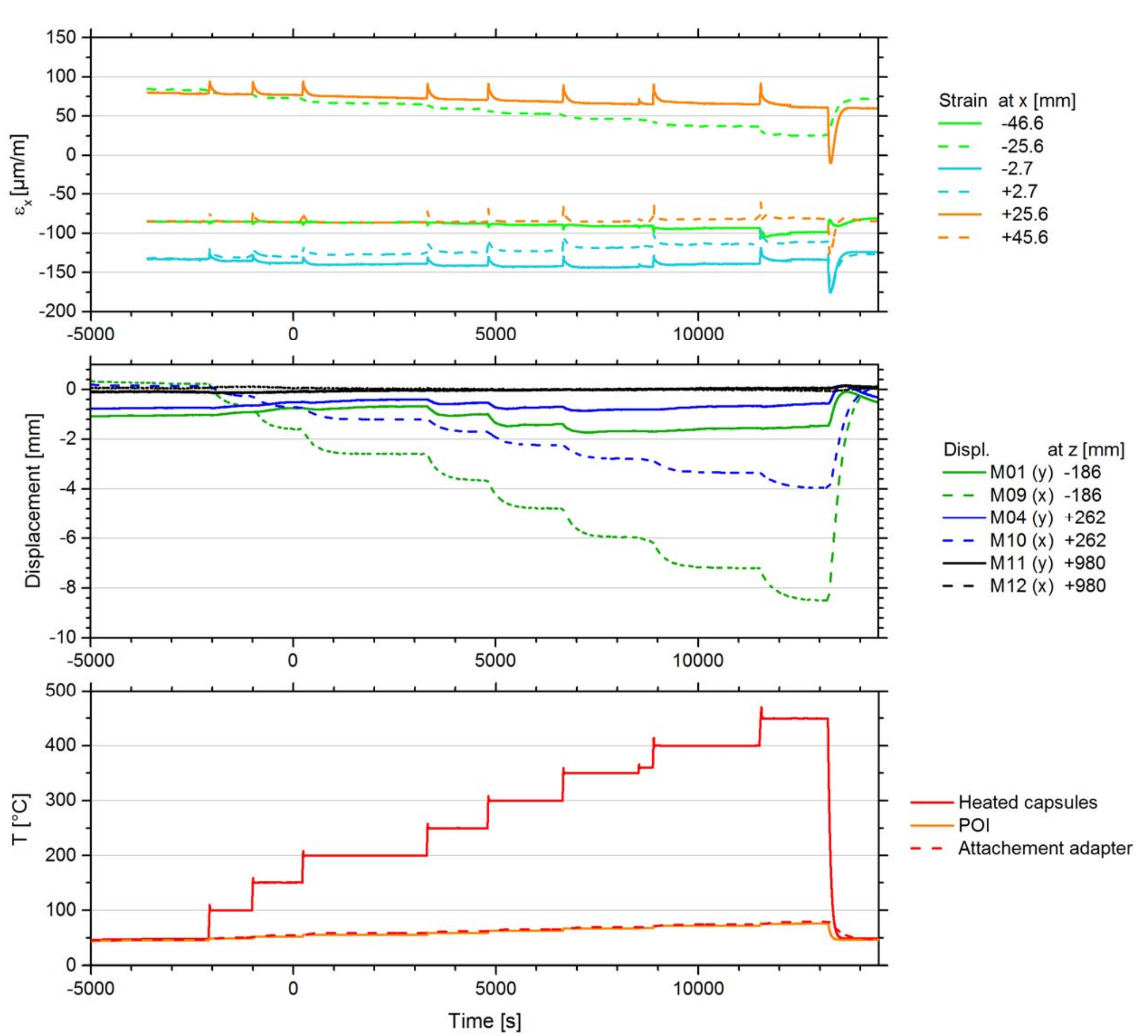

Test conditions:

- He mass-flow $14.6 \mathrm{~g} / \mathrm{s}$ (Comp. A), $18.0 \mathrm{~g} / \mathrm{s}$ (Comp. B)

- $50{ }^{\circ} \mathrm{C}$ compartment inlet bulk gas temperature

- $0.24 \mathrm{MPa}$ (abs.) compartment inlet pressure

Experimental Results:

- Maximum container surface temperature $80.9^{\circ} \mathrm{C}$

- Large deflection $(8.5 \mathrm{~mm})$ of container in $\mathrm{x}$-direction due to asymmetrical heating

- Maximum strain at fast temperature transient: (-)175 $\mu \mathrm{m} / \mathrm{m}$

- After capsule heater shut-down values for strain and displacement return to their initial, pre-heating state

$\rightarrow 1$. Reproduction of IFMIF relevant cooling flow conditions

$\rightarrow$ 2. Possibility to operate capsule $100 \mathrm{~K}$ above design point $\left(350{ }^{\circ} \mathrm{C}\right)$

$\rightarrow 3$. No indications for an excessive deformation of rigs or container
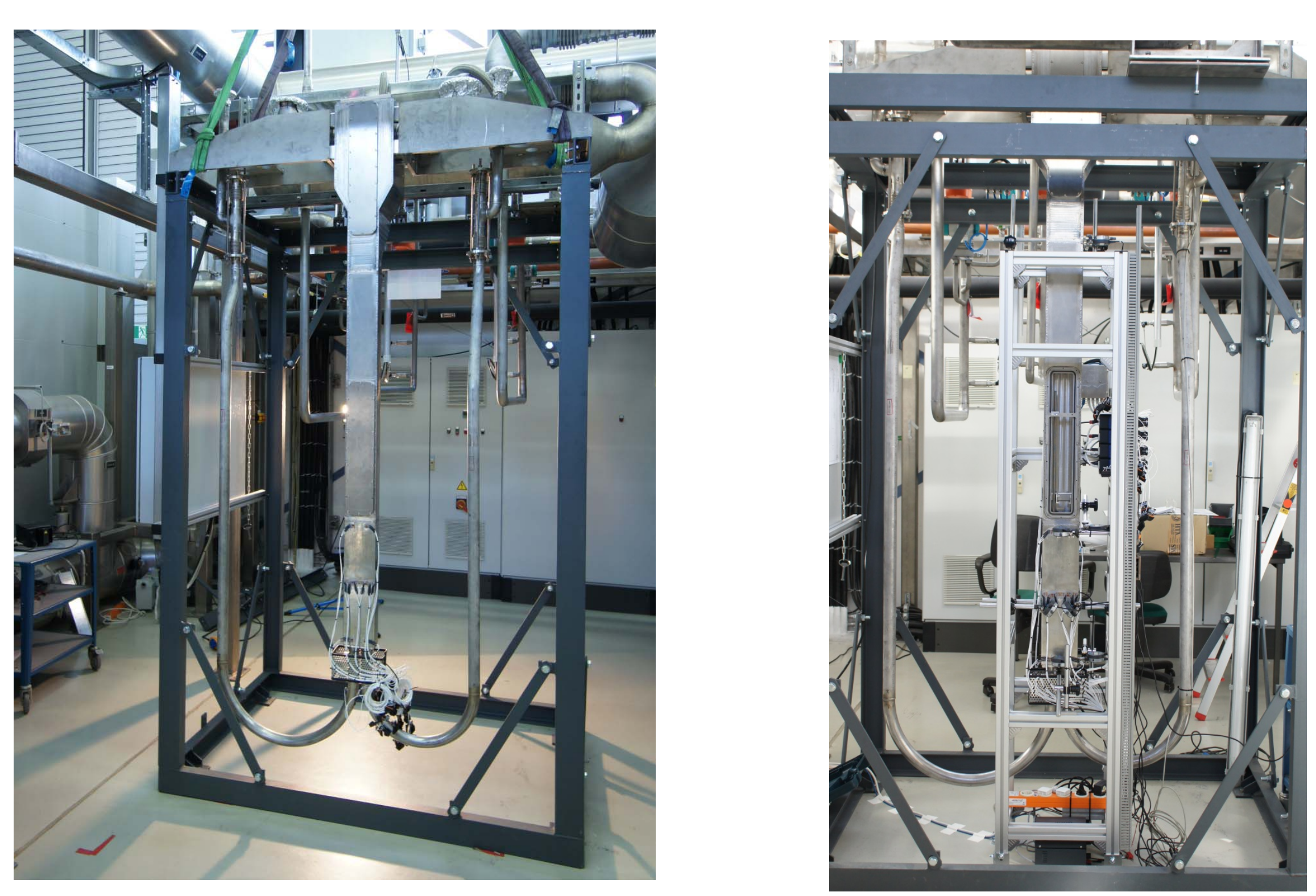

乃 georg.schlindwein@kit.edu

j +49 $721 / 608-23974$

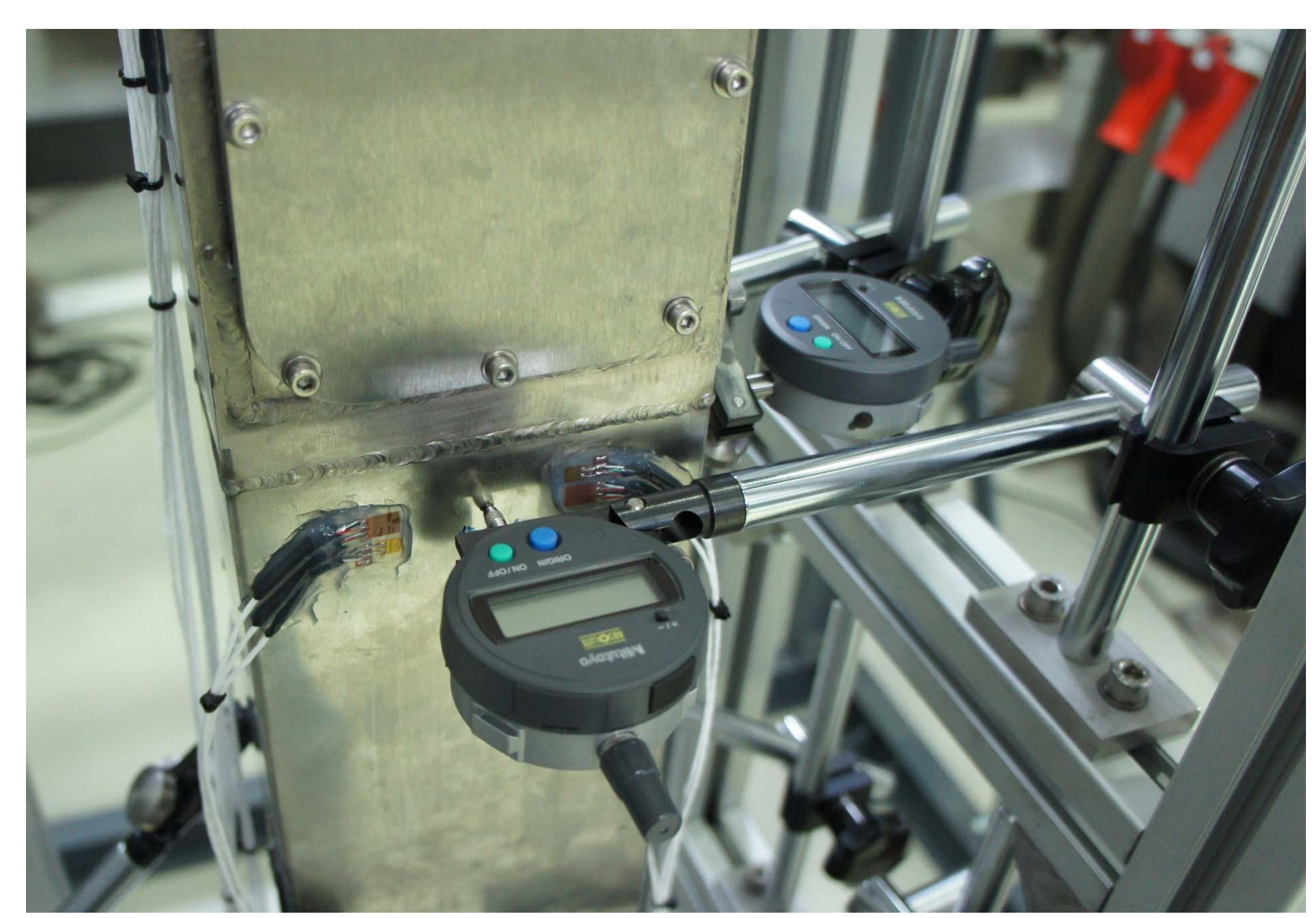

